\title{
An analysis of 2800 CT Head scans in patients with chronic headache
}

\section{Khare R. ${ }^{1}$, Khare A. ${ }^{2 *}$}

DOI: https://doi.org/10.17511/ijmrr.2019.i03.07

\footnotetext{
1 Rekha Khare, Associate Professor, Department of Radiology, Hind Institute of Medical Sciences, Barabanki, Uttar Pradesh, India.

2* A.K. Khare, Associate Professor, Department of Pharmacology and Honorary Physician, Hind Institute of Medical Sciences, Barabanki, Uttar Pradesh, India.
}

Introduction: Chronic headache is a common health problem in general medical practice and there is increasing demand of CT scan from specialist as well as non-specialist doctors to refer patients for CT head scan. Patients and methods: The present study was done on 2800 CT head scans of patients with problem of chronic headache. While patients in Group $1(n=1900)$ had only chronic headache without any neurological findings, Group B comprised of cases $(n=900)$ referred by specialist doctors after neurological examination. CT scan was done by trained technicians and contrast was injected where necessary. Results: Present study showed majority of patients in both group 1 and group 2 (90\% and $87.7 \%$ respectively) had normal CT findings or insignificant findings. However, difference was not significant in both groups when significant findings (10.0\% Gr. A and $12.2 \%$ Group B) were compared. Discussion: Our findings are consistent with other studies concluding that routine CT scan may not provide clinically useful information in chronic headache.

Keywords: Chronic headache, Migraine, Omnipaque

Corresponding Author

A.K. Khare, Associate Professor, Department of Pharmacology and Honorary Physician, Hind Institute of Medical Sciences, Barabanki, Uttar Pradesh, India. Email: akharester@gmail.com

\section{How to Cite this Article}

Khare R, Khare AK. An analysis of 2800 CT Head scans in patients with chronic headache. Int J Med Res Rev. 2019;7(3):190-194.

Available From

https://ijmrr.medresearch.in/index.php/ijmrr/article/ view/1057
To Browse

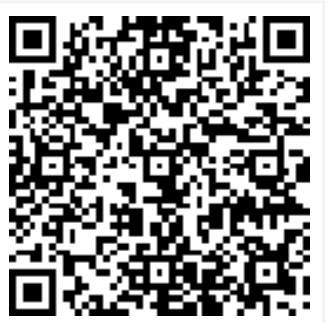

Manuscript Received 2019-05-08

Conflict of Interest No
Review Round 1 2019-05-18

Funding
Review Round 2 2019-05-24

Ethical Approval Yes
Review Round 3

Plagiarism X-checker $5 \%$
Accepted 2019-05-27

Note 


\section{Introduction}

The constant nature of chronic daily headaches makes them one of the most disabling headache conditions. Chronic daily headaches occur 15 days or more a month, for longer than three months. In a document on the global burden of headache, a prevalence of $50 \%$ has been reported in Asia, Australia, Europe and North America [1]. Chronic tension headache and Migraine are the most common causes of headache noted in populationbased survey on the prevalence of headache in the state of Karnataka [2]. Besides these common causes there are other causes for headache like trauma, infection, tumor, vascular, alcohol or drug abuse or may be related to ophthalmoplegic migraine [3].

CT and MRI two basic neuroimaging modality are available for the evaluation of various causes of headache, but CT being versatile, frequently available at many hospitals, comparatively cheaper than MRI and less time consuming, is usually the first investigation to be asked for in cases of chronic headaches. Many studies in past have shown that CT scan of vast majority of cases with chronic headache may be normal (4) so we need to have institutional guidelines for ordering CT scan [5]. Very little work has been published on the frequency of positive CT findings in the patients with headache and whether those are significant or just incidental [6]. The objective of this study was to assess the prevalence of normal CT scan in patients with chronic headache and to analyze other positive CT findings in this group of patients.

\section{Patients and Methods}

Type of study: It was retrospective open study. It is the analysis of all the CT head examinations done in the department of Hind institute of medical sciences Safedabad Barabanki.

Sample: Data were retrieved and evaluated from our medical records October 2014 to December 2018. A total of 2800 patients were included in the study. The patients of age groups of 5-75 years of either sex from different outpatient clinics, medical, psychiatry, pediatrics OPDs, self-referred cases for CT head examination in the department of radiodiagnosis of HIMS

CT scans were done on GE scanner 16 slice spiral CT scanner, $10 \mathrm{~mm}$ contiguous slices were done in standard position from foramen magnum to the
Vertex, slices were reconstructed into $3 \mathrm{~mm}$ slices wherever it was necessary and then cases were studied both in bone brain and subdural window. Contrast (omnipaque) was given wherever considered necessary in standard doses.

Exclusions: Patients with acute medical problems or those requiring surgical interventions were excluded.

Ethics: There were no ethical issues involved and study was permitted for publication by the institution.

Statistics: Descriptive statistics and Peaarson Chi square test was used to analyze the results.

\section{Results}

There were total of 2800 cases included in the study. Patients of either sex and in the range of 575 year were included.

Cases were divided in to two groups. Group A included 1900 patients with chronic headache as main complaint which was lasting for more than 3 months and occurring three or more times in a week. Group B included 900 patients of either sex with chronic headache as chief complaint and one of neurological signs like dizziness, tinnitus, nausea or vomiting, photophobia or neurological deficit on clinical examination.

In both the groups CT findings were categorized as follows.

\begin{tabular}{|l|l|}
\hline 1 & Normal scan \\
\hline 2 & Insignificant findings: \\
\hline & $\begin{array}{l}\text { a. Parenchymal calcification/calcified granuloma } \\
\text { b. cerebral atrophy consistent for age, } \\
\text { c. basal ganglion calcification basal ganglion calcification }\end{array}$ \\
\hline 3 & $\begin{array}{l}\text { Significant positive findings, which could possibly cause chronic } \\
\text { headache }\end{array}$ \\
\hline $\begin{array}{l}\text { a. Infection (Meningitis, cerebral abscess, sinusitis). } \\
\text { b. Focal gliosis/ mature infarct } \\
\text { c. Neoplasm/SOL with or without hydrocephalus } \\
\text { d. Intra cerebral or intraventricular or subarachnoid or Extra axial } \\
\text { hemorrhage } \\
\text { e. Miscellaneous finding ------ focal edema, white matter lesion } \\
\text { hemorrhage }\end{array}$ \\
\hline
\end{tabular}

*One case was strongly suspected to have arteriovenous malformation was referred to higher center for further imaging and management and hence excluded.

Normal and clinically insignificant CT findings were observed in both groups. 
Group A: 1710 cases (90\%) and Group B: 790 cases $(87.7 \%)$. Significant $C T$ findings were noted in both groups: Group A-190 cases (10\%) cases and Group B:110 cases (12.2\%). Findings are summarized in table 1.

\begin{tabular}{|c|c|c|c|c|c|c|}
\hline Category & & CT findings & $\left|\begin{array}{l}\text { No. in } \\
\text { GR. A }\end{array}\right|$ & $\%$ & $\left|\begin{array}{l}\text { No. in } \\
\text { GR. B }\end{array}\right|$ & $\%$ \\
\hline \multirow{5}{*}{$\begin{array}{l}\text { A. Normal Findings or } \\
\text { Insignificant CT Findings }\end{array}$} & 1 & Normal study & 1550 & 81.5 & 675 & 75 \\
\hline & 2 & $\begin{array}{l}\text { calcified } \\
\text { granuloma }\end{array}$ & 124 & 6.5 & 72 & 8 \\
\hline & 3 & $\begin{array}{l}\text { Generalized } \\
\text { cerebral } \\
\text { atrophy }\end{array}$ & 26 & 2.8 & 38 & 4.2 \\
\hline & 4 & $\begin{array}{l}\text { Basal ganglion } \\
\text { calcification }\end{array}$ & 10 & 1.1 & 5 & 0.5 \\
\hline & & Total & 1710 & $90 \%$ & 790 & $87.7 \%$ \\
\hline \multirow[t]{6}{*}{ B. Abnormal CT Findings } & 1 & Infection & 135 & 71 & 87 & 79.09 \\
\hline & 2 & Chronic infarct & 28 & 14.7 & 10 & 9 \\
\hline & 3 & Neoplasm & 10 & 5.2 & 5 & 4.5 \\
\hline & 4 & Hemorrhage & 15 & 7.8 & 5 & 4.5 \\
\hline & 5 & Miscellaneous & 2 & 1.05 & 3 & 2.7 \\
\hline & & Total & 190 & $10 \%$ & 110 & $\begin{array}{l}12.22 \\
\%\end{array}$ \\
\hline
\end{tabular}

CT findings in Group A (patients referred by non specialist GPs) and Group B (patients referred by specialist doctors) show majority of patients in both groups had normal CT findings or insignificant findings

\section{Discussion}

According to US headache consortium, neuroimaging should be considered in patients who have non acute headache with significant abnormal findings on neurological examination (Grade B recommendation) [5].

Many people who have headaches want a CT scan or an MRI to find out if their headaches are caused by a serious problem, such as a brain tumor. Denying a patient basic neuroimaging is an ethical issue as sometimes this investigation can lead to diagnosis of life- threatening disease e.g. Brain tumor [6]. However, a CT scan of the head uses a low radiation dose. This may slightly increase the risk of harmful effects. Risks from radiation exposure may add up, so it is best to avoid unnecessary radiation.

$\mathrm{CT}$ the first basic imaging modality is easily available, comparatively affordable, and quick, therefore, often utilized as screening modality for headache.
We evaluated the head CT of patients with chronic headache referred to our Radiology department to see if this test can provide useful information for diagnosis of such a common complaint.

In 1993, Mitchell et al. conducted study onComputed tomography in the headache patients and concluded that routine computed tomography of the brain in patients with chronic headache but with normal physical and neurological exam or any other unusual clinical symptom have a low likelihood ratio for discovering significant intracranial disease. They studied 350 cases and only 7 patients (2\%) had CT head findings that were clinically significant [4].

In another study by Dumas et al. 402 CT scans of patients with chronic headache revealed minor findings that did not alter patient management, only 4 out of $402(0.98 \%)$ had diagnosis of aneurysm Osteoma and low-grade glioma [7].

Study by Frishberg concluded that a routine CT examination for chronic headache in absence of focal neurological sign or any abnormal symptoms is less likely to have a CT scan with positive findings [8]. Since year 2000, multiple guidelines have recommended against routine neuroimaging in patients with headaches because a serious intracranial pathologic condition is an uncommon cause. However, demand for CT scans has only increased amongst GPs, patients and their family members.

Our study revealed that 2225 (79.4\%) patients with normal head CT (both groups combined) and $160+115=275(-9.8 \%)$ patients having incidental CT findings too with headache only, while patients $190+110=300(10.71 \%)$ had significant CT findings which is much more than reported in the study by Mitchell et al [4].

Aneurysm was suspected in one of our study too, patient was referred to higher center for further management. Our observations differ from some previous studies.

Thomas [9] studied 215 CT scans for patients with chronic headache, significant abnormalities were noted in $3(1.4 \%), 22(10.2 \%)$ had nonsignificant findings and 190 (88.4) had normal scan. It was for open access brain $\mathrm{CT}$ service in cases of chronic headache so that GPs could reduce the number of referrals to secondary care.

Simpson et al. assessed the impact of this open access service. 
They found positive findings in $10.5 \%$ in 4404 CT scans referred by general physicians between 1999 to 2007 . Out of this $1.4 \%$ of the CT findings were thought of having abnormalities which could potentially be the cause of headache while $9.1 \%$ findings were incidental [10].

Results of our study show that number of patients in Group A presenting with chronic headache as the only symptom was $190(10 \%)$ who had significant findings in $\mathrm{CT}$, while in group B of patients with chronic headache having some neurological signs had significant findings in $110(12.2 \%)$ though it was not statistically significant $(P>0.1$ on Chi square test).

Number of patients in group A with normal head CT was $81.5 \%$, while those in group B was $75 \%$ i.e.6.5\% more than Group B. $(P<-01)$. This highlights the fact that patients presenting with chronic headache only without any neurological sign are more likely to have normal CT scan. while number of normal CT scan significantly lesser in patients with neurological sign

This our present study showed much more positive findings in head CT scan compared to contemporary studies. There are many reasons for this difference

01. Referral cases to our department come from any OPD or indoor wards of our medical college, many times patients come directly from free health camp or from primary health care centers, private medical practitioners etc., not necessarily referred by neuro-physicians.

02. Calcified granuloma with or with out neurological symptoms were found in $196(7 \%)$ in Head CT scan. It seems reasonable as tuberculosis and neuro-cysticercosis are the very common causes of calcified granuloma. These two entities are not uncommon in our poor socioeconomic catchment area. Our results were very much consistent with the results of study done by Gupta et al [6].

03. This was followed by CT finding of generalized cerebral atrophy. Most cases with these findings were from age group of over 60 years and few were with cerebral palsy and chronic infarct, 38 $(1.35 \%)$. Study done by Simpson found cerebral atrophy in $1.5 \%$ and infarcts in $1 \%$ cases. However, our results were slightly higher. [10]

04. Finding in our study in relation to age is comparable to the study of Gupta et al [6]. There were two main findings; calcified granuloma (196) and infection (222).
Neoplasm mainly metastasis was seen mostly frequently in older age group $15(0.53 \%)$. Two cases of Meningioma in Head CT scan of women and 3 cases of Posterior fossa tumors were noted in our study.

\section{Conclusion and Recommendations}

Results of many contemporary studies show a low yield of positive findings and and close to $80 \%$ normal CT scan in the patients with chronic headache only. In present study also, the positive $\mathrm{CT}$ findings are low but not as low as reported by few earlier studies.

Also, certain CT findings like chronic granuloma and infection are commoner in younger age group while cerebral atrophy and neoplasm was seen mainly in elderly. how often should the scan be repeated if headache continues? We conclude and emphasize that doing CT scan unselectively in patients with chronic headache in absence of any clue to neurological deficit is not truly justified as headache is so common, that it is neither practicable nor costeffective to scan everybody. It becomes impossible. If everyone with headache simply joined a queue for a scan, some people with intracranial bleeding would die while waiting and some with tumors would die before they are scanned.

\section{What this study adds to existing knowledge?}

Chronic headache is common problem and demand for CT scan is increasing.

This study showed that majority of patients had normal findings or insignificant findings, it follows that, even if we can afford to scan everyone, doctors must be critical and use clinical skills to prioritize the scans to minimize costs and risks involved.

\section{Contribution by Authors}

All CT scans were interpreted by the first author while all clinical data were seen and interpreted by second and corresponding author who was also responsible for manuscript preparation and revisions.

Declaration: Authors have used authentic data for the study and there were no ethical issues involved. 
Permission to publish study was obtained from institutional authorities. Authors did not receive any financial assistance. There was no conflict of interest.

\section{Reference}

01. Stovner Lj, Hagen K, Jensen R, et al. The global burden of headache- $a$ documentation of headache prevalence and disability worldwide. Cephalalgia. 2007 Mar;27(3)193-210.

DOI: $10.1111 /$ j.1468-2982.2007.01288.x [Crossref]

02. Rao GN, Kulkarni GB, Gururaj G, et al. The burden of headache disorders in Indiamethodology and questionnaire validation for a community-based survey in Karnataka State. J Headache Pain. 2012 Oct;13(7)543-50.

doi: 10.1007/s10194-012-0474-1 [Crossref]

03. Ambrosetto P, Nicolini F, Zoli $M$, et al. Ophthalmoplegic migraine- from questions to answers. Cephalalgia. 2014 Oct;34 (11)914-9.

doi: $10.1177 / 0 \quad 333102414523843 \quad$ [Crossref]

04. Mitchell CS, Osborn RE, Grosskreutz SR. Computed tomography in the headache patientis routine evaluation really necessary?. Headache. 1993 Feb;33(2)82-6.

[Crossref]

05. American academy of neurology. Evidence based guidelines in the primary care settingNeuroimaging in patients with nonacute headache. 2010;20 April 2014. Available at:

[Article] [Crossref]

06. Gupta V, Khandelwal N, Prabhakar A, Kumar A S, Ahuja K C, Singh Paramjeet. Prevalence of normal head $\mathrm{CT}$ and positive $\mathrm{CT}$ findings in a large cohort of patients with chronic headaches. Neuroradiol J. 2015 Aug;28(4)421-425.

[Crossref]

07. Dumas M D, Pexman J H and Kreeft $\mathrm{JH}$. Computed tomography evaluation of patients with chronic headache. Can Med Assoc J. $1994 ; 151 ; 1447-1452$.

[Crossref]

08. Frishberg BM. The utility of neuroimaging in the evaluation of headache in patients with normal neurologic examinations. Neurology. 1994 Jul;44(7)1191-7.

DOI: $10.1212 /$ wnl.44.7.1191 [Crossref]
09. Thomas R, Cook A, Main G, et al. Primary care access to computed tomography for chronic headache. $\mathrm{Br}$ J Gen Pract. 2010 Jun;60(575)426-30.

doi: 10.3399/bjgp10X502146 [Crossref]

10. Simpson GC, Forbes K, Teasdale E, et al. Impact of GP direct-access computerised tomography for the investigation of chronic daily headache. Br J Gen Pract. 2010 Dec; 60(581)897-901. doi: 10.3399/bjgp10X544069 [Crossref]

11. Nagra I, Wee B, Short J, et al. The role of cranial CT in the investigation of meningitis. JRSM Short Rep. 2011 Mar 23;2(3)20.

doi: 10.1258/shorts.2011.010113 [Crossref] 